\title{
Hypertension Associated with Atherosclerosis Risk Factors in Patients of Family Health Strategy Highlighting the Framingham Risk Score
}

\author{
Bruna Lais da Silva Coutinho', Rosana Andrade Brito', \\ Ana Isabel Cezário de Carvalho Conceição ${ }^{1}$, Fabíola de Jesus Cardoso ${ }^{1}$, \\ Andreza Silva dos Santos', Bruno Felipe Ferreira Lopes', Rubson Dantas da Silva1, \\ Polyane Medeiros Alves ${ }^{1}$, Raiane dos Santos Pereira ${ }^{1}$, Álvaro Luís Müller da Fonseca ${ }^{2 *}$ \\ ${ }^{1}$ Department of Education (DEDC7), Universidade do Estado da Bahia (UNEB), \\ Senhor do Bonfim, Brazil \\ ${ }^{2}$ Immunology Laboratory (LAIM), Department of Education (DEDC7), Universidade do Estado da Bahia (UNEB), \\ Senhor do Bonfim, Brazil \\ Email: *alfonseca@uneb.br
}

How to cite this paper: da Silva Coutinho, B.L., Brito, R.A., de Carvalho Conceição, A.I.C., de Jesus Cardoso, F., dos Santos, A.S., Lopes, B.F.F., da Silva, R.D., Alves, P.M., dos Santos Pereira, R. and da Fonseca, Á.L.M. (2018) Hypertension Associated with Atherosclerosis Risk Factors in Patients of Family Health Strategy Highlighting the Framingham Risk Score. Open Journal of Preventive Medicine, 8, 229-247. https://doi.org/10.4236/ojpm.2018.88020

Received: July 9, 2018

Accepted: August 12, 2018

Published: August 15, 2018

Copyright $\odot 2018$ by authors and Scientific Research Publishing Inc. This work is licensed under the Creative Commons Attribution International License (CC BY 4.0).

http://creativecommons.org/licenses/by/4.0/

\begin{abstract}
The Systemic Arterial Hypertension (SAH) stands out among the chronic non-transmissible pathologies that impact the cause and/or aggravation of cardiovascular diseases (CVD) on a global level, as the disease is an underestimated disorder due to non-perceptive symptoms and associated with factors and risk markers of another CVD. Therefore, establishing the risk of progression and aggravation of the $\mathrm{SAH}$, according the Framingham Risk Score (FRS), allows to reducing morbidity and improving preventative measures for DCVs. This observational and transversal study approaches the data collection of patient records at the Health Family Strategy of Senhor do Bonfim, BA, which established differences by descriptive and inferential statistical analysis (correlation and regression). The aspects of hypertension associated with risk factors for atherosclerosis were analyzed, determining the risk of developing cardiovascular events in 10 years by FRS. From 432 families, 746 patients were selected, of which 340 are hypertensive individuals $(\mathrm{SAH}=45.57 \%)$ and $406(\mathrm{NSAH}=54.42 \%)$ non-hypertensives. Among the SAH the majority (31.17\%) was in the age range of $63-77$, but, in both groups, women were in stronger number. There was greater prevalence in $\mathrm{SAH}$ for all the characteristics analyzed, smoking (13.20\%), sedentary (29.41\%) and cardiovascular accident (22.60\%). The SAH group is more susceptive to the CVD progress in 10 years by FRS ( $\mathrm{P}<0.0001$ ANOVA). In the NSAH group, there were significant associations among all the variables
\end{abstract}


analyzed as was expected, without differences between the linear correlation and regression, indicating the physio-metabolic equilibrium of the factors and markers evaluated by FRS. Already in SAH group, despite the correlations have been significant too, the regression analysis revealed that only Total Cholesterol $(\mathrm{P}=0.0086)$; LDL $(\mathrm{P}<0.0001)$, Glucose $(\mathrm{P}<0.0006)$ and Age $(\mathrm{P}<0.0001)$ have significative association with FRS. So, these factors and markers deserve more attention upon the health staff of Health Family Strategy, in the SAH course at studied population, attempt the highest cardiovascular risk by FRS (2.5 to 2.8 times) to SAH. The monitoring of high-risk patients should prioritize the lifestyle changes, employing preventive measures to $\mathrm{SAH}$ and CVD and atherosclerosis.

\section{Keywords}

Hypertension, Risk Factors, Atherosclerosis, Cardiovascular Diseases, Framingham Risk Score, Family Health Strategy

\section{Introduction}

The atherosclerosis is a chronic inflammatory disease with a multifactorial origin that happens as a response to endothelial damage and affects in special the intimae layer of arteries with medial and great caliber [1]. It is a disease that several factors come to have a contribution to degenerate the arterial wall, characterized by the deposition of oxidized LDL molecules and macrophages in the intimal vase layer, forming plaques that reduce vascular light and compromise blood flow [2] and is notable that the intensity and duration of injuries determine the alterations levels. A lot of factors have been reported like co-responsible by atherosclerosis progression, as overwork and stress of urban life, allied to ingesting food consumed outside the home, called Fast Foods and the industrialized snacks, can be considered villains that when associated with other risk factors seems to have a significant contribution to increase the pathological prevalence of atherosclerosis and associated diseases as hypertension and diabetes [3].

Most individuals with atherosclerosis present one or more risk factors [4]. Among the most regular are hypertriglyceridemia, hypercholesterolemia, smoking, obesity, diabetes mellitus, sedentary lifestyle and the family history of premature arterial diseases [5]. Obesity is the most relevant [6] and associate to, especially, age, gender, hereditary, alimentary diet, dyslipidemia, smoking, physical activity, diabetes mellitus, left ventricular hypertrophy, psychosocial factors, besides systolic arterial hypertension [7].

Arterial hypertension (AH) is a strong risk factor to diseases as atherosclerosis and thrombosis that show up by cardiac, renal, cerebral, and vascular peripheral problem events. It represents $25 \%$ of the multifactorial etiologic causes of ischemic cardiopathy and $40 \%$ of vascular cerebral accidents [8] [9]. The $\mathrm{AH}$ presents multifactorial cause, has an insidious chronic character more prevalent in the adult and elderly population, and is characterized by high and sustained 
levels of blood pressure (BP), usually above the target (systolic blood pressure level $\geq 140 \mathrm{mmHg}$ and/or diastolic blood pressure level $\geq 90 \mathrm{mmHg}$ ) [10]. All these $\mathrm{AH}$ consequences resulting from cardiovascular diseases make it the most important cause of reduction upon life quality and life expectative of the individuals [11].

The AH incidence presents relevant augment in adults and can achieve $20 \%$ and keep rising according to the age to $80 \%$ of the population over 80 years of age. The incidence of $\mathrm{AH}$ is lower in women until menopause as well as the associated disease if compares to the men. Therefore, as soon as the menopause begins, the women present $\mathrm{AH}$ incidence increasing and practically become equal to the men $\mathrm{AH}$ incidence. It is believed that estrogen deficiency, lipid profile alterations, weight raise and sedentary way of life (sedentariness) were the critical factors associated to the higher $\mathrm{AH}$ women incidence in menopause in comparison to the pre-menopause ones [12]. Since it is a clinical condition associated with high mortality, also noted that most hypertension persons present comorbidities such as diabetes, dyslipidemia, smoking or family history of atheromatosis. An important aspect of this condition is that the combination of these risk factors for the development of CVD is greater than the sum of each one isolated. Thus, the hypertensive approach should consider the individual characteristics, such as the coexistence of other risk factors or markers and lesions of target organs [13].

The straight and positive relation between high $\mathrm{AH}$ and cardiovascular risk is constant, non-dependent, predictive, consistent and is very significant to individuals with or without coronary artery disease and occurs in both genders, several age ranges, ethnic groups and socioeconomic and cultural levels [14].

\section{Methods}

\subsection{Population Studied}

Along May 2014 and June of 2017, it was performed in this observational and transversal study involving 2161 families registered in FHS. The Family Health Strategy is a policy for monitoring chronic and non-transmissible diseases in Brazil, including hypertension and diabetes, concerned to the Basic Attention Program attempted by "Sistema Único de Saúde-SUS" supported by Health Ministry of the Federal Government of Brazil at the Family Healthy Unities from Senhor do Bonfim, Bahia, Brazil. From those registered families, it was selected, by convenience, 432 families to the assessment of 3325 medical records to analyze the Systemic Arterial Hypertension prevalence and determine the Framingham Risk Score. This amount represents $1 / 5$ of the total, a sample size that is enough to assure the statistical significance power of the study. The statistical significance of the sample size (study power) was obtained second Santos [15], and determined in at least 249 individuals, with a sampling error of 5\% (CI 0.95) for a population from 700 patients.

Those 432 families were evaluated and separated in two groups (I and II) with 216 families each, from the first one was clustered at Hypertension group (SAH) and from the second, the non-Hypertension group (NSAH). For both groups (I 
and II), it was assumed as arrangement and analysis criteria that individuals must present age equal or over 18 years that present plasmatic lipoproteins laboratorial data in their medical records. The patients subscribe the Free Consentient and Clarified Term (FCCT) permitting the data collected from medical cards and bank data of the FHS.

To classify the patients according to the blood pressure, the criteria were obtained from 7th Brazilian Guidelines for Arterial Hypertension [16], as follows for SAP (Systolic arterial pressure) and DAP (Diastolic arterial pressure) in $\mathrm{mm}$ $\mathrm{Hg}$, respectively:

\begin{tabular}{ccc}
\hline Normal & $\leq 120$ & $\leq 80$ \\
\hline Pre-hypertension & $121-139$ & $81-89$ \\
Stage 1 hypertension & $140-159$ & $90-99$ \\
Stage 2 hypertension & $160-179$ & $100-109$ \\
Stage 3 hypertension & $\geq 180$ & $\geq 110$ \\
\hline
\end{tabular}

When the SAP and DAP were into separated categories, the biggest was used for classification. The systolic hypertension was considered isolated if SAP $\geq 140$ $\mathrm{mm} \mathrm{Hg}$ and DAP $<90 \mathrm{~mm} \mathrm{Hg}$.

This work does not present any ethical relevant conflicts. The research project was approved by Ethical Research Commit of the UNEB (CEP-UNEB), number 2096650 (CAAE 64201517.1.0000.0057).

\subsection{Collection and Data Analysis}

All the data were obtained from patients' medical records and FHS data bank. It was collected data about age, gender, pressure blood assessment, glycemia, plasmatic lipoproteins (CT, LDL-C, HDL-C, TG) and life habits (smoking, sedentariness, alcohol ingestion [alcoholism]), overweight/obesity and cardiovascular previous events. The last laboratorial exam of every patient was taking as a premise for SAH (Systemic Arterial Hypertensive patients) and NSAH (Non-Systemic Arterial Hypertensive patients) groups.

The family members were classified into lipid profile categories according the “V Diretriz Brasileira de Dislipidemias e Prevenção da Aterosclerose” [17]:

\begin{tabular}{|c|c|c|c|}
\hline CT: & $<200$-Desirable; & 200 to $239-$ Borderline; & $\geq 240-$ High \\
\hline \multirow[t]{2}{*}{ LDL-C: } & $<100-$ Optimal; & 100 to129-Desirable, & 130 to $159-$ Borderline; \\
\hline & 160 to 189 High; & $\geq 190$-Very High. & \\
\hline HDL-C: & $>60$-Desirable; & $<40-$ Low. & \\
\hline TG: & $<150-$ Desirable; & 150 to 200 -Borderline; & 200 to $499-$ High; \\
\hline \multirow{3}{*}{ non-HDL-C: } & $\geq 500$ - Very High. & & \\
\hline & $<130-$ Optimal; & 130 to $159-$ Desirable; & \\
\hline & 160 to $189-$ High, & $\geq 190$-Very High. & \\
\hline
\end{tabular}




\subsection{Statistical Analysis}

The FRS was determined by the percentage value of the risk to developing cardiovascular disease over the next 10 years, resulting in subgroups according to the lower category $(<10 \%)$, medium $(10 \%$ to $20 \%)$ and high risk $(>20 \%)$. The differences between groups and subgroups by variance and comparative analyses were also determined.

As recommended by the Brazilian Health Ministry [18], to carry out the calculation for the risk of a patient, the Framingham risk values corresponding to scores according to age, sex (gender), blood pressure assessment, total cholesterol, HDL, LDL, in addition to the diabetes mellitus diagnosis and the smoking habit were assessed. Therefore, for each item, in this table, score values will be assigned, which will be summed up for each total percentage that will be determine the risk of developing some cardiovascular disease over 10 years.

The statistical determination of the distribution was made by the method of d'Agostino \& Pearson, but in groups with little data it was used the method of Kolmogorov-Smirnov. When comparing, the Pearson (parametric) and Spearman (non-parametric) methods were adopted. The comparative analysis of dispersion and variability involving three or more groups was made by One-way ANOVA test. According to the determined distribution, for the comparative analyses between the two groups were used the tests T, Mann-Whitney (non-parametric) and non-pared (parametric). The program GraphPad Prism 5.0.1 (GraphPad Software Inc., 2007, La Jolla, USA) was performed.

\section{Results}

Among the patient participants, there were 917 individuals and after the application of the evaluation criteria, only 746 were selected; from this amount 340 were confirmed as hypertensive and, by the way, it was included in SAH group, representing $45.57 \%$ of the sample amount. The non-hypertensive group (NSAH) remains 406 patients $(54.42 \%)$ of the total sample able to the study.

The FRS determined to SAH: 111 (32.6\%) low risk, medium 137 (40.2\%), and high (27.0\%) and 92 for the NSAH: 321 (79.0\%) low risk, medium 48 (11.8\%) and high $37(9.1 \%)$. The risk to SAH was estimated at 2.5 to 2.8 times bigger than the NSAH group risk by FRS.

The assessment between the risk subgroups by FRS between SAH and NSAH showed significant variance $(P=0.0001$, ANOVA) and are also significantly different from each other ( $\mathrm{P}=0.0001$, Mann-Whitney), as well as the paired analysis between the low risk subgroups $(\mathrm{P}=0.0001$, Mann-Whitney), medium $(\mathrm{P}=0.0001$, Mann-Whitney $)$ and high risk $(\mathrm{P}=0.0003$, paired T-Test) (Figures 1-4).

It was observed that the most part of the SAH individuals was between 63 and 77 years old (36.17\%) and the NSAH between 33 and 47 (36.45\%), and the most of studied population was compound by women in both groups $(75.0 \% \mathrm{SAH}$ and 67.7\% NSAH, Table 1 and Table 2). 


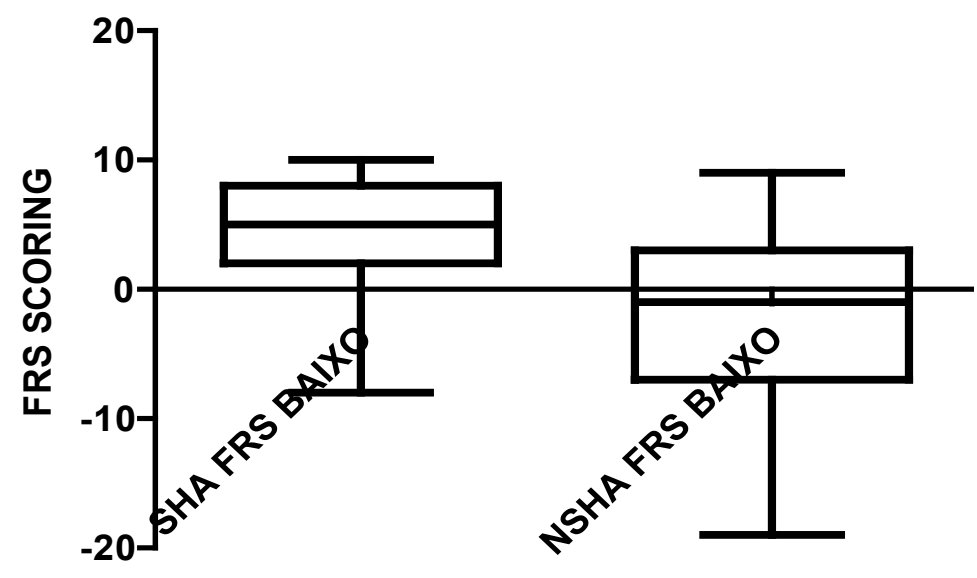

$$
P \text { value } \quad \mathbf{0 . 0 0 0 1 ( M a n n ~ W h i t n e y ~ t e s t ) ~}
$$

Figure 1. Comparing SAH and NSAH FRS low levels.

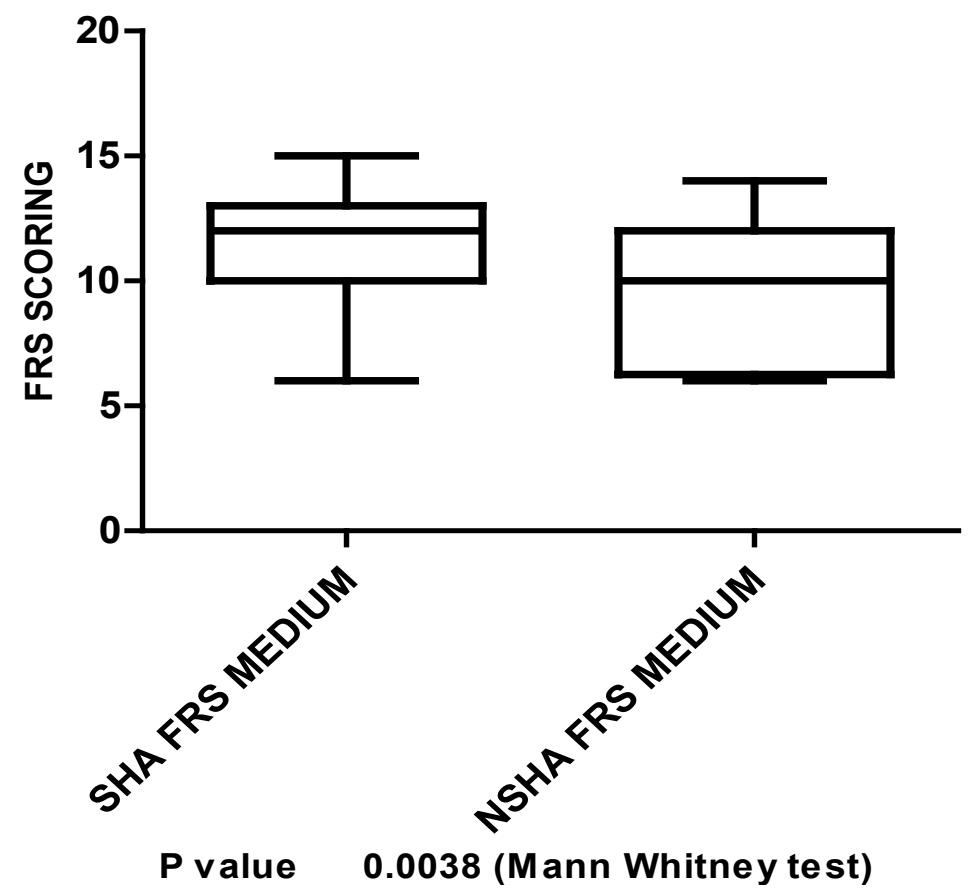

Figure 2. Comparing SAH and NSAH FRS medium levels.

The analysis of variance for FRS risk level between the strata of age presented high significance $(\mathrm{P}<0.0001$, ANOVA), as well as for the age ranges in SAH group and for NHAS group separated each other also presented the same variance very significative.

The multiple comparative analysis (Tukey Test) for the age ranges between SAH and NSAH revealed significance only when comparing the age range from 33 to 47 and 48 to 62 years. However, the comparative T-test for the same age ranges between SAH and NSAH has shown that only the range of 18 to 32 years has no significant difference. 


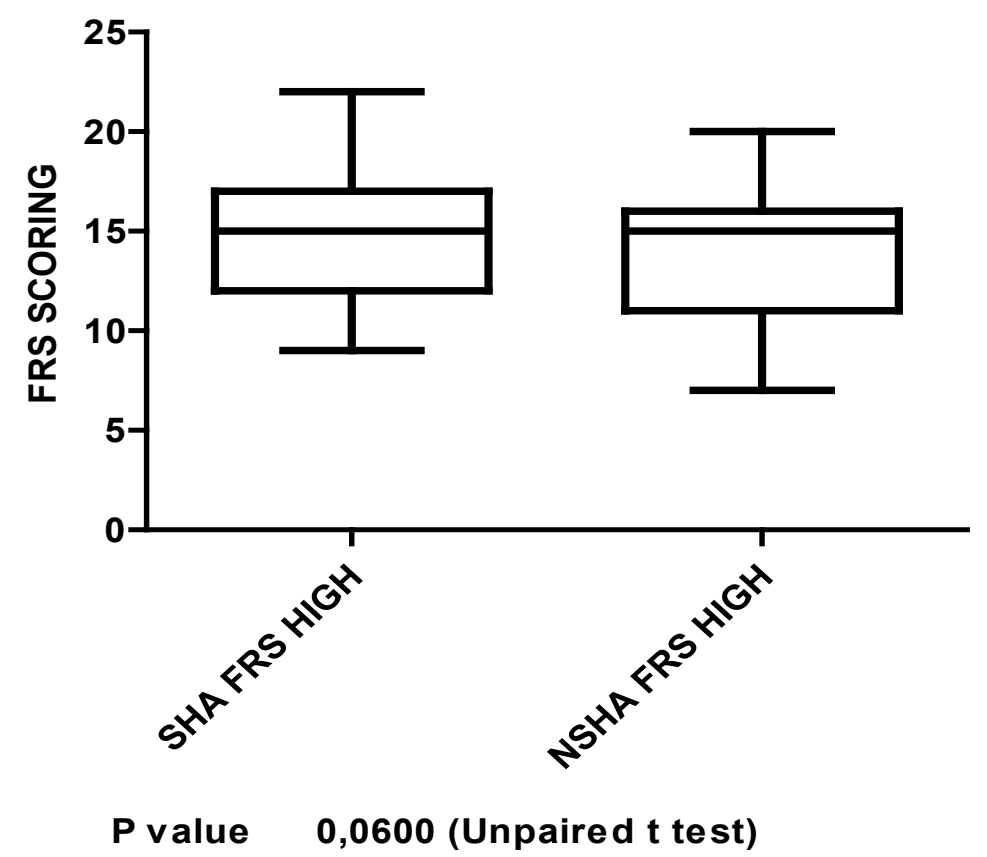

Figure 3. Comparing SAH and NSAH FRS high levels.

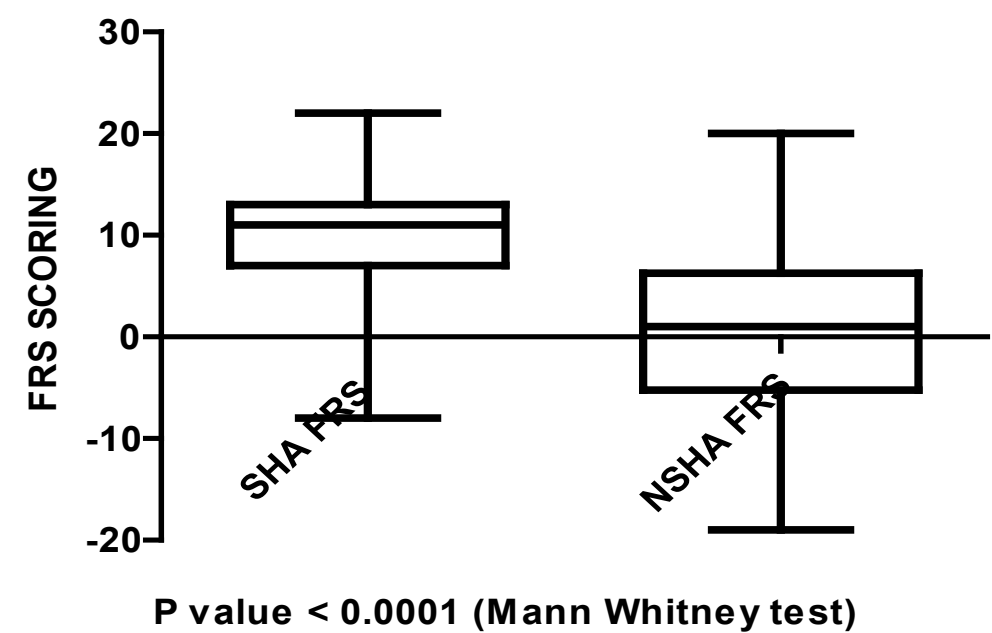

Figure 4. Comparing SAH and NSAH FRS levels.

Table 1. SAH group risk level per gender and range age.

\begin{tabular}{|c|c|c|c|c|c|c|c|}
\hline \multirow[b]{2}{*}{ Age range } & \multicolumn{2}{|c|}{ Low risk $<10 \%$} & \multicolumn{2}{|c|}{ Medium risk $10 \%-20 \%$} & \multicolumn{2}{|c|}{ High risk $>20 \%$} & \multirow[b]{2}{*}{ Total } \\
\hline & $\mathbf{M}$ & $\mathrm{F}$ & $\mathbf{M}$ & F & $\mathbf{M}$ & $\mathrm{F}$ & \\
\hline $18-32$ & 0 & 3 & 1 & 0 & 0 & 0 & 4 \\
\hline $33-47$ & 7 & 31 & 1 & 4 & 1 & 0 & 44 \\
\hline $48-62$ & 12 & 23 & 10 & 43 & 12 & 10 & 110 \\
\hline $63-77$ & 5 & 22 & 3 & 44 & 18 & 31 & 123 \\
\hline $78-92$ & 1 & 7 & 7 & 24 & 7 & 13 & 59 \\
\hline Total & 25 & 86 & 22 & 115 & 38 & 54 & 340 \\
\hline
\end{tabular}

M-Masculine; F-Feminine. 
Table 2. NSAH risk level per gender and range age.

\begin{tabular}{cccccccc}
\hline & \multicolumn{2}{l}{ Low risk $<\mathbf{1 0} \%$} & \multicolumn{4}{l}{ Medium risk $\mathbf{1 0 \%}-\mathbf{2 0} \%$} & \multicolumn{2}{l}{ High risk $>\mathbf{2 0 \%}$} & \\
\hline Age range & M & F & M & F & M & F & Total \\
\hline $\mathbf{1 8}-\mathbf{3 2}$ & 23 & 75 & 0 & 0 & 0 & 0 & 98 \\
$\mathbf{3 3}-\mathbf{4 7}$ & 48 & 96 & 2 & 2 & 0 & 0 & 148 \\
$\mathbf{4 8}-\mathbf{6 2}$ & 21 & 40 & 9 & 16 & 3 & 11 & 100 \\
$\mathbf{6 3}-\mathbf{7 7}$ & 6 & 7 & 4 & 9 & 10 & 9 & 45 \\
$\mathbf{7 8}-\mathbf{9 2}$ & 0 & 5 & 1 & 5 & 4 & 0 & 15 \\
Total & 98 & 223 & 16 & 32 & 17 & 20 & 406 \\
\hline
\end{tabular}

M-Masculine; F-Feminine.

The variance analysis for FRS risk level between the gender strata ( $\mathrm{M}$ and F) was high significative $(\mathrm{P}<0.0001$, ANOVA). The same was verified for the group SAH isolated and for the NSAH showing that high variance.

The multiple comparison analysis (Tukey Test) for the FRS risk levels by gender in SHA did not reveal significance only for the low-risk level grouping. In turn, in NSAH, the same comparison analysis did not reveal significance just for high-risk level.

Already the comparison by $\mathrm{T}$ test for FRS risk level between women and men grouping in SAH only, showed significant differences between all score risk strata. The same occurred for NSAH. When this type of test was performed between FRS risk levels for feminine grouping only, but between SAH and NSAH, there were also significant differences among all risk strata. The same was verified for the masculine grouping between SAH and NSAH.

The analysis of life habits activities shows that the SAH present higher prevalence about every studied characteristic, highlighting the high indexes of smoking (13.20\%), sedentary lifestyle (29.41\%) and Cardiovascular Accident (22.60\%).

There was significant difference between $\mathrm{SAH}$ and NSAH for the plasmatic lipoprotein markers LDL $(\mathrm{P}=0.0334)$, TC $(\mathrm{P}=0.0003)$, TG $(\mathrm{P}=0.0216)$ in general and TG of desirable profile $(\mathrm{P}=0.0103)$. The other markers do not show any significant difference.

The linear correlation tests of the markers presented positive significant correlation for LDL and TC $(\mathrm{P}<0.0001)$ and TC and TG $(\mathrm{P}<0.0005)$ in the SAH group (Table 3 ). For the other markers, there were no significant differences (Table 4).

As expected, correlation analyses showed that, in SAH and NSAH groups, all analyzed variables present significant association with FRS, since these markers and risk factors are associated precisely to assess the degree of risk cardiovascular (Table 3 and Table 4). However, when regression analyses are carried out, only TC $(\mathrm{P}=0.0086)$, LDL $(\mathrm{P}=0.0001)$, Glucose $(\mathrm{P}=0.0006)$ and Age $(\mathrm{P}=0.0001)$ have their associations with FRS confirmed in SAH (Table 5). 
Table 3. Linear correlation among risk factors in SHA.

\begin{tabular}{|c|c|c|c|c|c|c|c|c|}
\hline & $\mathrm{TC}$ & LDL & TG & HDL & VLDL & GLUC. & AG & FRS \\
\hline \multirow{4}{*}{ TC } & & $\mathrm{n}=319$ & $\mathrm{n}=179$ & $\mathrm{n}=327$ & $\mathrm{n}=\mathbf{2 0 5}$ & $n=265$ & $\mathrm{n}=337$ & $\mathrm{n}=337$ \\
\hline & & $\mathrm{r}=0.8747$ & $\mathrm{r}=-0.0828$ & $r=0.2490$ & $r=0.2576$ & $r=0.1383$ & $\mathrm{r}=0.09580$ & $r=0.4956$ \\
\hline & & $P<0.0001$ & $\mathrm{P}=0.2703$ & $\mathrm{P}<0.0001$ & $P=0.0002$ & $P=0.0244$ & $\mathrm{P}=0.0791$ & $\mathrm{P}<0.0001$ \\
\hline & & $\#(\mathrm{~b})$ & $(\mathrm{ns})(\mathrm{b})$ & $\#(\mathrm{~b})$ & \#(b) & $\#(b)$ & $(\mathrm{ns})(\mathrm{a})$ & $\#$ (b) \\
\hline \multirow{4}{*}{ LDL } & $\mathrm{n}=319$ & & $\mathrm{n}=168$ & $\mathrm{n}=320$ & $\mathrm{n}=204$ & $\mathrm{n}=254$ & $\mathrm{n}=322$ & $\mathrm{n}=322$ \\
\hline & $r=0.8747$ & & $\mathrm{r}=-0.1551$ & $\mathrm{r}=0.05764$ & $\mathrm{r}=0.1295$ & $\mathrm{r}=0.1195$ & $r=0.1183$ & $r=0.5875$ \\
\hline & $\mathrm{P}<0.0001$ & & $\mathrm{P}=0.0649$ & $\mathrm{P}=0.3040$ & $\mathrm{P}=0.0649$ & $\mathrm{P}=0.0572$ & $P=0.0339$ & $\mathrm{P}<0.0001$ \\
\hline & $\#(\mathrm{~b})$ & & (ns)(b) & (ns)(b) & $(\mathrm{ns})(\mathrm{b})$ & $(\mathrm{ns})(\mathrm{b})$ & $\#(a)$ & $\#(\mathbf{b})$ \\
\hline \multirow{4}{*}{ TG } & $\mathrm{n}=179$ & $\mathrm{n}=168$ & & $\mathrm{n}=173$ & $\mathrm{n}=105$ & $\mathrm{n}=133$ & $\mathrm{n}=182$ & $\mathrm{n}=182$ \\
\hline & $\mathrm{r}=-0.0828$ & $\mathrm{r}=-0.1551$ & & $\mathrm{r}=-0.06221$ & $\mathrm{r}=-0.04108$ & $\mathrm{r}=0.05398$ & $\mathrm{r}=-0.08538$ & $\mathrm{r}=0.1703$ \\
\hline & $\mathrm{P}=0.2703$ & $P=0.0649$ & & $\mathrm{P}=0.4162$ & $\mathrm{P}=0.6774$ & $\mathrm{P}=0.5371$ & $\mathrm{P}=0.2518$ & $\mathrm{P}=0.02115$ \\
\hline & $(\mathrm{ns})(\mathrm{b})$ & $(\mathrm{ns})(\mathrm{b})$ & & (ns)(b) & $(\mathrm{ns})(\mathrm{b})$ & $(\mathrm{ns})(\mathrm{b})$ & $(\mathrm{ns})(\mathrm{a})$ & $\#$ (b) \\
\hline \multirow{4}{*}{ HDL } & $\mathrm{n}=327$ & $\mathrm{n}=320$ & $\mathrm{n}=173$ & & $\mathrm{n}=\mathbf{2 0 5}$ & $\mathrm{n}=258$ & $\mathrm{n}=330$ & $\mathrm{n}=330$ \\
\hline & $\mathrm{r}=0.2490$ & $\mathrm{r}=0.05764$ & $\mathrm{r}=-0.06221$ & & $r=-0.2759$ & $\mathrm{r}=-0.03228$ & $\mathrm{r}=-0.00164$ & $\mathrm{r}=-0.2151$ \\
\hline & $\mathrm{P}<0.0001$ & $\mathrm{P}=0.3040$ & $\mathrm{P}=0.4162$ & & $P<0.0001$ & $\mathrm{P}=0.6058$ & $\mathrm{P}=0.9762$ & $\mathrm{P}<0.0001$ \\
\hline & $\#(\mathrm{~b})$ & (ns)(b) & (ns)(b) & & $\#$ (b) & $(\mathrm{ns})(\mathrm{b})$ & $(\mathrm{ns})(\mathrm{a})$ & $\#(\mathrm{~b})$ \\
\hline \multirow{4}{*}{ VLDL } & $\mathrm{n}=205$ & $\mathrm{n}=204$ & $\mathrm{n}=105$ & $\mathrm{n}=\mathbf{2 0 5}$ & & $\mathrm{n}=161$ & $\mathrm{n}=206$ & $n=206$ \\
\hline & $r=0.2576$ & $\mathrm{r}=0.1295$ & $\mathrm{r}=-0.04108$ & $\mathrm{r}=-0.2759$ & & $r=0.3161$ & $\mathrm{r}=0.03304$ & $r=0.3203$ \\
\hline & $P=0.0002$ & $\mathrm{P}=0.0649$ & $\mathrm{P}=0.6774$ & $\mathrm{P}<0.0001$ & & $P<0.0001$ & $\mathrm{P}=0.6373$ & $\mathrm{P}<0.0001$ \\
\hline & (b) & $(\mathrm{ns})(\mathrm{b})$ & $(\mathrm{ns})(\mathrm{b})$ & $\#(\mathrm{~b})$ & & $\#(b)$ & $(\mathrm{ns})(\mathrm{a})$ & $\#$ (b) \\
\hline \multirow{4}{*}{ GLUC. } & $\mathrm{n}=265$ & $\mathrm{n}=254$ & $\mathrm{n}=133$ & $\mathrm{n}=258$ & $\mathrm{n}=161$ & & $\mathrm{n}=265$ & $\mathrm{n}=265$ \\
\hline & $r=0.1383$ & $\mathrm{r}=0.1195$ & $\mathrm{r}=0.05398$ & $\mathrm{r}=-0.03228$ & $\mathrm{r}=0.3161$ & & $r=0.1717$ & $r=0.3237$ \\
\hline & $P=0.0244$ & $\mathrm{P}=0.0572$ & $\mathrm{P}=0.5371$ & $\mathrm{P}=0.6058$ & $P<0.0001$ & & $P=0.0051$ & $\mathrm{P}<0.0001$ \\
\hline & $\#(\mathrm{~b})$ & (ns) (b) & $(\mathrm{ns})(\mathrm{b})$ & $(\mathrm{ns})(\mathrm{b})$ & $\#$ (b) & & $\#(\mathbf{a})$ & $\#(a)$ \\
\hline \multirow{4}{*}{ AG } & $\mathrm{n}=337$ & $\mathrm{n}=322$ & $\mathrm{n}=182$ & $\mathrm{n}=330$ & $\mathrm{n}=206$ & $\mathrm{n}=265$ & & $\mathrm{n}=340$ \\
\hline & $\mathrm{r}=0.09580$ & $\mathrm{r}=0.1183$ & $\mathrm{r}=-0.08538$ & $\mathrm{r}=-0.00164$ & $\mathrm{r}=0.03304$ & $r=0.1717$ & & $\mathrm{r}=0.4516$ \\
\hline & $\mathrm{P}=0.0791$ & $P=0.0339$ & $\mathrm{P}=0.2518$ & $\mathrm{P}=0.9762$ & $\mathrm{P}=0.6373$ & $P=0.0051$ & & $\mathrm{P}<0.0001$ \\
\hline & $(\mathrm{ns})(\mathrm{a})$ & $\#(\mathfrak{a})$ & $(\mathrm{ns})(\mathrm{a})$ & $(\mathrm{ns})(\mathrm{a})$ & $(\mathrm{ns})(\mathrm{a})$ & $\#(\mathrm{a})$ & & $\#$ (b) \\
\hline \multirow{4}{*}{ FRS } & $\mathrm{n}=337$ & $\mathrm{n}=322$ & $\mathrm{n}=182$ & $\mathrm{n}=330$ & $\mathrm{n}=206$ & $\mathrm{n}=265$ & $\mathrm{n}=340$ & \\
\hline & $\mathrm{r}=0.4956$ & $\mathrm{r}=0.5875$ & $r=0.1703$ & $\mathrm{r}=-0.2151$ & $r=0.3203$ & $r=0.3237$ & $r=0.4516$ & \\
\hline & $\mathrm{P}<0.0001$ & $\mathrm{P}<0.0001$ & $P=0.02115$ & $\mathrm{P}<0.0001$ & $P<0.0001$ & $P<0.0001$ & $\mathrm{P}<0.0001$ & \\
\hline & $\#$ (b) & $\#(\mathrm{~b})$ & $\#$ (b) & $\#(\mathrm{~b})$ & \#(b) & $\#$ (a) & $\#$ (b) & \\
\hline
\end{tabular}

Note: TC-Total Cholesterol, LDL-Low Density Lipoprotein, TG-Triglycerides, HDL-High Density Lipoprotein, VLDL-Very Low Density Lipoprotein, GLUC-Glucose, AG_Age, FRS—Framinghan's Risk Score.

By the way, between the NSAH, also as expected, the regression confirms the association among all the variables, demonstrating that healthy individuals 
Table 4. Linear correlation among risk factors in NSHA.

\begin{tabular}{|c|c|c|c|c|c|c|c|c|}
\hline & TC & LDL & TG & HDL & VLDL & GLUC. & AG & FRS \\
\hline \multirow{4}{*}{ TC } & & $\mathrm{n}=389$ & $\mathrm{n}=195$ & $\mathrm{n}=395$ & $\mathrm{n}=284$ & $\mathrm{n}=375$ & $\mathrm{n}=404$ & $n=404$ \\
\hline & & $r=0.8247$ & $r=0.2389$ & $\mathrm{r}=0.1740$ & $\mathrm{r}=0.4776$ & $\mathrm{r}=0.1463$ & $\mathrm{r}=0.3748$ & $\mathrm{r}=0.5254$ \\
\hline & & $\mathrm{P}<0.0001$ & $P=0.0008$ & $P=0.0005$ & $\mathrm{P}<0.0001$ & $P=0.0045$ & $\mathrm{P}<0.0001$ & $\mathrm{P}<0.0001$ \\
\hline & & $\#(\mathfrak{b})$ & $\#(\mathrm{~b})$ & $\#(\mathrm{~b})$ & $\#$ (b) & $\#(b)$ & $\#(\mathrm{~b})$ & $\#$ (b) \\
\hline \multirow{4}{*}{ LDL } & $\mathrm{n}=389$ & & $\mathrm{n}=186$ & $\mathrm{n}=391$ & $\mathrm{n}=285$ & $\mathrm{n}=366$ & $\mathrm{n}=391$ & $\mathrm{n}=391$ \\
\hline & $\mathrm{r}=0.8247$ & & $r=0.1502$ & $\mathrm{r}=-0.04982$ & $\mathrm{r}=0.2594$ & $r=0.1177$ & $\mathrm{r}=0.3020$ & $r=0.5115$ \\
\hline & $P<0.0001$ & & $\mathrm{P}=0.0408$ & $\mathrm{P}=0.3258$ & $P<0.0001$ & $P=0.0243$ & $\mathrm{P}<0.0001$ & $P<0.0001$ \\
\hline & $\#(\mathrm{~b})$ & & (ns)(b) & (ns)(b) & $\#$ (b) & $\#(\mathrm{~b})$ & $\#(\mathrm{~b})$ & $\#(\mathrm{~b})$ \\
\hline \multirow{4}{*}{ TG } & $\mathrm{n}=195$ & $\mathrm{n}=186$ & & $\mathrm{n}=289$ & $n=182$ & $\mathrm{n}=240$ & $n=296$ & $n=296$ \\
\hline & $\mathrm{r}=0.2389$ & $\mathrm{r}=0.1502$ & & $\mathrm{r}=-0.02354$ & $\mathrm{r}=0.2541$ & $r=0.04969$ & $r=0.2938$ & $\mathrm{r}=0.3253$ \\
\hline & $P=0.0008$ & $\mathrm{P}=0.0408$ & & $\mathrm{P}=0.6902^{(\mathrm{ns})(\mathrm{b})}$ & $P=0.0005$ & $\mathrm{P}=0.4435^{(\mathrm{ns})(\mathrm{b})}$ & $\mathrm{P}<0.0001$ & $\mathrm{P}<0.0001$ \\
\hline & $\#(\mathrm{~b})$ & $(\mathrm{ns})(\mathrm{b})$ & & & $\#$ (b) & & $\#(\mathrm{~b})$ & $\#(b)$ \\
\hline \multirow{4}{*}{ HDL } & $\mathrm{n}=395$ & $\mathrm{n}=391$ & $\mathrm{n}=289$ & & $\mathrm{n}=285$ & $\mathrm{n}=368$ & $\mathrm{n}=397$ & $\mathrm{n}=397$ \\
\hline & $\mathrm{r}=0.1740$ & $\mathrm{r}=-0.04982$ & $\mathrm{r}=-0.02354$ & & $\mathrm{r}=-0.1043$ & $\mathrm{r}=0.01338$ & $\mathrm{r}=0.02942$ & $\mathrm{r}=-0.1698$ \\
\hline & $P=0.0005$ & $\mathrm{P}=0.3258$ & $\mathrm{P}=0.6902^{(\mathrm{ns})(\mathrm{b})}$ & & $\mathrm{P}=0.0788$ & $\mathrm{P}=0.7981^{(\mathrm{ns})(\mathrm{b})}$ & $\mathrm{P}=0.5589$ & $P=0.0007$ \\
\hline & $\#$ (b) & $(\mathrm{ns})(\mathrm{b})$ & & & $(\mathrm{ns})(\mathrm{b})$ & & $(\mathrm{ns})(\mathrm{b})$ & $\#(\mathfrak{b})$ \\
\hline \multirow{4}{*}{ VLDL } & $\mathrm{n}=284$ & $\mathrm{n}=\mathbf{2 8 5}$ & $\mathrm{n}=182$ & $\mathrm{n}=285$ & & $\mathrm{n}=362$ & $\mathrm{n}=410$ & $\mathrm{n}=410$ \\
\hline & $r=0.4776$ & $r=0.2594$ & $\mathrm{r}=0.2541$ & $\mathrm{r}=-0.1043$ & & $\mathrm{r}=0.1460$ & $r=0.2756$ & $\mathrm{r}=0.4125$ \\
\hline & $\mathrm{P}<0.0001$ & $\mathrm{P}<0.0001$ & $\mathrm{P}=0.0005$ & $\mathrm{P}=0.0788$ & & $P=0.0054$ & $\mathrm{P}<0.0001$ & $\mathrm{P}<0.0001$ \\
\hline & $\#$ (b) & $\#(b)$ & $\#(\mathrm{~b})$ & (ns)(b) & & $\#(b)$ & $\#$ (b) & $\#(\mathrm{~b})$ \\
\hline \multirow{4}{*}{ GLUC. } & $\mathrm{n}=375$ & $\mathrm{n}=366$ & $\mathrm{n}=240$ & $\mathrm{n}=368$ & $\mathrm{n}=362$ & & $\mathrm{n}=377$ & $\mathrm{n}=377$ \\
\hline & $\mathrm{r}=0.1463$ & $\mathrm{r}=0.1177$ & $\mathrm{r}=0.04969$ & $\mathrm{r}=0.01338$ & $r=0.1460$ & & $\mathrm{r}=0.2358$ & $r=0.2790$ \\
\hline & $P=0.0045$ & $P=0.0243$ & $\mathrm{P}=0.4435^{(\mathrm{ns})(\mathrm{b})}$ & $\mathrm{P}=0.7981^{(\mathrm{ns})(\mathrm{b})}$ & $P=0.0054$ & & $\mathrm{P}<0.0001$ & $\mathrm{P}<0.0001$ \\
\hline & $\#(b)$ & $\#(b)$ & & & $\#$ (b) & & $\#(b)$ & $\#$ (b) \\
\hline \multirow{4}{*}{ AG } & $\mathrm{n}=404$ & $\mathrm{n}=391$ & $\mathrm{n}=296$ & $\mathrm{n}=397$ & $n=410$ & $\mathrm{n}=377$ & & $n=406$ \\
\hline & $\mathrm{r}=0.3748$ & $\mathrm{r}=0.3020$ & $\mathrm{r}=0.2938$ & $\mathrm{r}=0.02942$ & $\mathrm{r}=0.2756$ & $\mathrm{r}=0.2358$ & & $\mathrm{r}=0.8651$ \\
\hline & $\mathrm{P}<0.0001$ & $P<0.0001$ & $\mathrm{P}<0.0001$ & $\mathrm{P}=0.5589$ & $\mathrm{P}<0.0001$ & $P<0.0001$ & & $\mathrm{P}<0.0001$ \\
\hline & $\#(b)$ & $\#(\mathrm{~b})$ & $\#(\mathrm{~b})$ & (ns)(b) & $\#$ (b) & $\#(\mathbf{b})$ & & $\#(b)$ \\
\hline \multirow{4}{*}{ FRS } & $\mathrm{n}=404$ & $\mathrm{n}=391$ & $\mathrm{n}=296$ & $\mathrm{n}=397$ & $n=410$ & $\mathrm{n}=377$ & $\mathrm{n}=406$ & \\
\hline & $\mathrm{r}=0.5254$ & $\mathrm{r}=0.5115$ & $r=0.3253$ & $r=-0.1698$ & $\mathrm{r}=0.4125$ & $\mathrm{r}=0.2790$ & $\mathrm{r}=0.8651$ & \\
\hline & $\mathrm{P}<0.0001$ & $\mathrm{P}<0.0001$ & $P<0.0001$ & $P=0.0007$ & $\mathrm{P}<0.0001$ & $P<0.0001$ & $\mathrm{P}<0.0001$ & \\
\hline & $\#(\mathrm{~b})$ & $\#(b)$ & $\#(\mathrm{~b})$ & $\#(b)$ & $\#(\mathrm{~b})$ & $\#(b)$ & $\#(\mathrm{~b})$ & \\
\hline
\end{tabular}

Note: TC-Total Cholesterol, LDL-Low Density Lipoprotein, TG-Triglycerides, HDL-High Density Lipoprotein, VLDL-Very Low Density Lipoprotein, GLUC-Glucose, AG-Age, FRS-Framinghan's Risk Score.

maintain the physio-metabolic equilibrium corresponding to the prevalent lowest levels of risk determined by FRS (Table 6). 


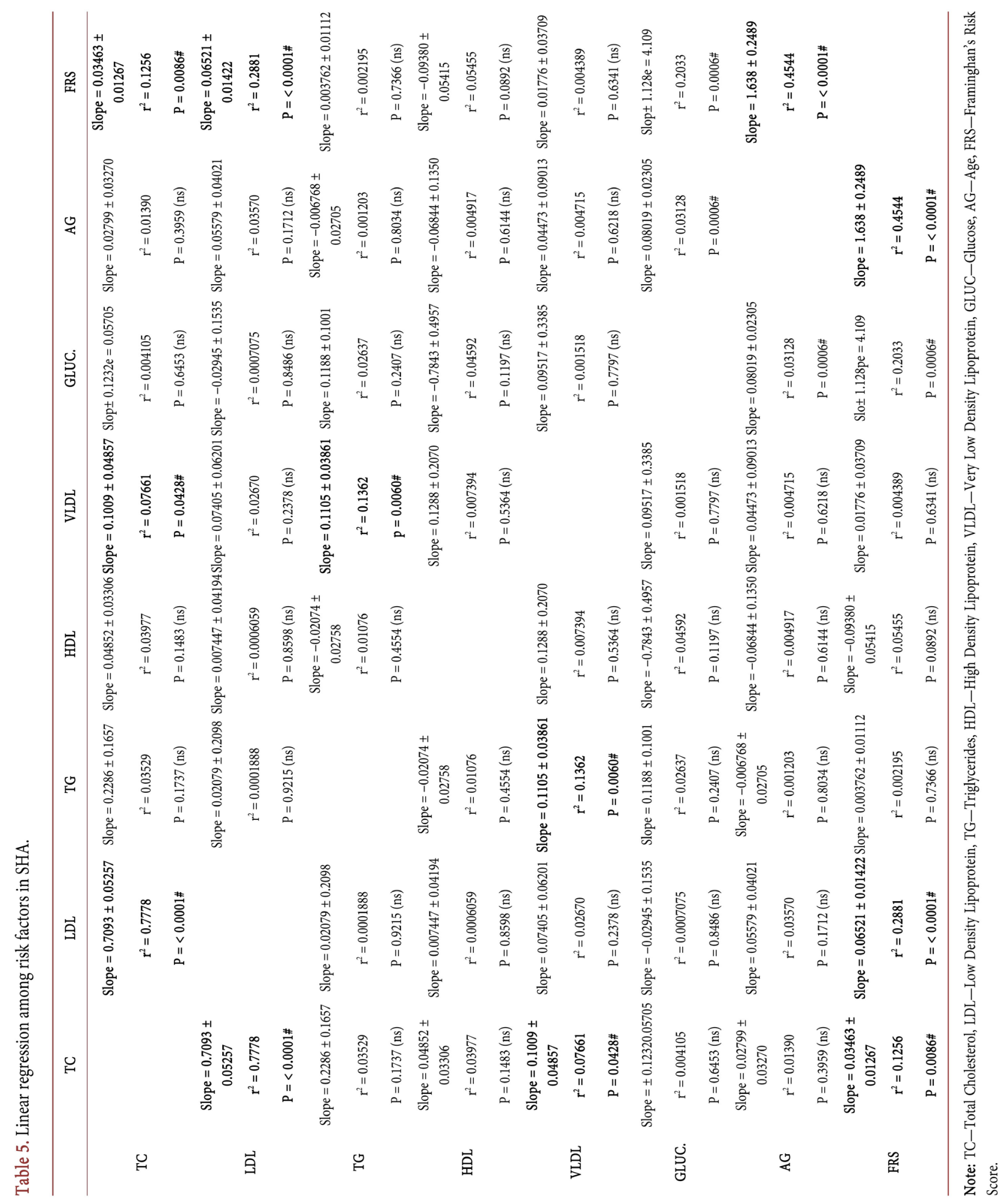

\section{Discussion}

The atherosclerosis is the sickness that causes the higher morbidity and mortality indexes in the world. The atherosclerotic lesion is the most common abnormality found in the artery, resulting from two basic events: cholesterol accumulation and 


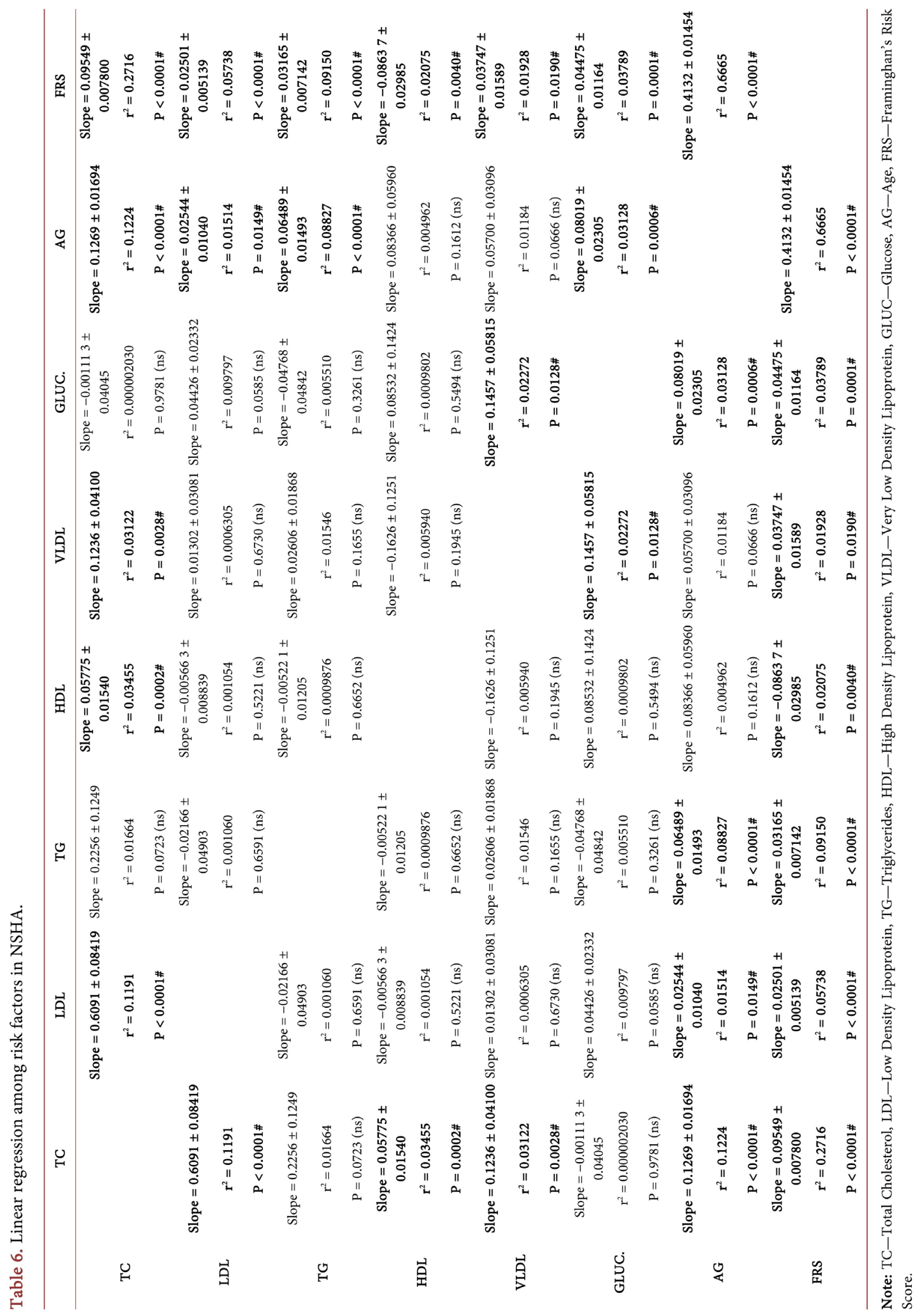


smooth muscle cells proliferation inside the intimal tunic that drives to the inflammation. This process produces a fibrous plaque, which it is spread out to the vase lumen and modifies the medial tunic, inducing several circulatory complications due the inflammatory response trigged inside the arterial vase wall [19].

The relation between SAH and coronary disease is very complex and concern to other risk factors. The SAH promotes an endothelial dysfunction, aggravates the atherosclerotic process and collaborates to atherosclerotic plaque instability. Frequently complications of SAH like left ventricular hypertrophy provokes a diminishing flux of the coronary vascular reserve, elevation on oxygen consume by myocardium and competition with the perivascular fibrous formations, making difficulty the oxygen support of the myocardial cells. Such changes in the hypertensive patient are aggravated by aging and by habit factors (for example, the great salt consume on diet) [20].

$\mathrm{SAH}$ is considered the most important factor to healthy in many countries, including Brazil, and is one of the most common risk factors to the development of cardiovascular diseases. Because of its impact on cardiovascular morbimortality, it is necessary for the monitoring and treatment of this illness [21].

The total population studied was predominant compound by feminine gender in SAH group (75.0\%), as well as in NSAH (67.7\%), that could explain the high women prevalence at all analyzed aspects. These data maybe indicate that women are more frequent users of the health services than men. Otherwise, after 50 years old (a great part of the people studied presenting over 50 years old) the incidence of the risk factors on women, like hypertension and dyslipidaemias, together circulatory problems, becomes equal to the men. It is believed that the estrogen deficiency and posterior loss of protector effect of this hormone result in alterations of the lipid profile (LDL elevation, HDL reducing), weight raise and sedentariness. Then, these are critical factors related to higher incidence of arterial hypertension among women at menopause if compares to pre-menopause ones [22].

The clinical sample profile reveals that SAH presents elevated indexes for smoking (13.20\%), sedentariness (29.41\%), Cardiovascular Accident (22.60\%). The aggravation of dyslipidaemias, with the diminishing HLD levels and elevating LDL and TG levels are the main consequences of smoking and provoke arterial pressure alterations [23], a rise of the sanguine flux at the coronary arteries, increase of contractility and debit cardiac [24], elevation of glucose plasmatic levels, besides the basic cause of respiratory insufficiency disease [25].

From the linear correlation tests, a significant association was obtained for LDL and CT $(\mathrm{P}<0.0001)$ in the SAH group. LDL is one of the fractions of the $\mathrm{CT}$, which justifies the significant data found. Excessive LDL is considered a substantial risk factor in triggering the atherosclerotic lesion. This may be related to extrinsic and/or intrinsic factors, such as an exacerbated intake of saturated fats, genetic factors producing a catabolism fall of this protein by the liver or an increase in endogenous cholesterol synthesis, resulting in 
Hypercholesterolemia [18]. Moreover, these genetic factors when related to the extrinsic factors, act synergistically accelerating the atherosclerotic process and causing greater clinical repercussions [1].

The SAH group presents a high prevalence of smoking, obesity, and sedentariness, getting related to the Framingham study [26] [27]. Also, it is notable that the cardiovascular problems are most frequent among the hypertensive people if presents two risk factors at last, showing that the risk events are proportional to the association with the number of risk factors incident in the population. By the way, it is possible to associate the arterial pressure elevation with other factors and to suppose that these individuals have a tendency to develop circulatory complications and vascular damages.

There was a significant difference of LDL levels between SAH and NSAH, which is similar to the related by other study [28] that analyses the incidence of dyslipidaemias in hypertensive individuals, such as the undesirable lipid profile found in $62.1 \%$ of the cases, but $37.9 \%$ in non-hypertensive ones. Since a long time ago it is known that the lipid profile, especially of cholesterol and their fractions have a direct influence on heart ischemic disease, revealing the higher the cholesterolemia, the bigger the risk [29]. A higher level of low density lipoprotein (LDL) fraction increases the appearance of the atherosclerotic disease. On another hand, a higher level of the high density lipoprotein (HDL) fraction lowers the risk of the atherosclerosis [30]. The LDL fraction of hypertensive patients is more easily oxidized when compared to LDL of normotensive individuals. The LDL oxidized (ox-LDL) modifies the endothelial function and the vascular reactivity. It is believed that the ox-LDL is a fundamental agent to the atherogenesis, since it induces the leukocyte adhesion molecules due to its mitogenic properties on the macrophages and vascular smooth muscle cells, besides disturbing the production of endothelial nitric oxide, the most powerful vascular dilator and inhibitor of plaque aggregation [30].

Pieces of Evidence in some studies make believe that the LDL oxidized (ox-LDL) is the critical factor involved in the start of the atherosclerotic lesion [31]. The LDL excess in the plasmatic compartment could be a result of a hyper-caloric and unbalance diet and due to the endogenous synthesis of cholesterol or even due to the low levels of LDL catabolism in the liver, provoked by a genetic defect that causes a deficiency in the expression or in their receptors function, resulting in hypercholesterolemia [32]. However, these genetic factors form a complex interaction with environmental factors, which implies in the LDL concentration in the plasma [18].

This study shows significant differences between TC-SAH and TC-NSAH levels and TG-SAH and TG-NSAH. Observational studies reveal a positive correlation between the total cholesterol (TC) levels and arterial pressure in the general population and in hypertensive patients [33]. The association between those two risk factors is not very clear yet. It is known that the physio-pathological mechanisms involved in hypertension and dyslipidaemia share metabolic abnormali- 
ties in common, which can act in synergism or even improve the atherogenic process. The hypercholesterolemia can have primary effect in the vases and vascular tonus, besides promoting an endothelial dysfunction, also present in arterial hypertension but by incipient way [34].

The HDL is involved in the atherosclerotic process, but it's also related to cardiovascular diseases by an inversed way [35]. No significant differences between HDL-SAH and HDL-NSAH were found in this study, in contradiction to the other ones [36] that show that the HDL reduction is associated to arterial hypertension, therefore the highest thrombotic risk could be present in these patients. The anti-atherogenic effect of HDL occurs basically due to the action of the cholesterol transport from the peripheral cells to the liver. Besides, the modulation of the inflammatory function and the oxidative process by inhibition of endothelial adhesion cell molecules, as well as the intervention in the action of chemokines, Kappa- $\beta$ nuclear factor, and LDL oxidation [37]. However, this lipoprotein has others important functions, in addition to a role in a reverse transport of cholesterol (RTC), those were attested by several experimental models and epidemiologic studies. Such functions comprise mediation of the cholesterol efflux, lymphocyte activation, induction of nitric oxide production, regulation of the sanguine coagulation and the platelets activity [38].

The HDL particle has an anticoagulant effect by activated protein C (APC) stimulation, which has an important function in the inactivation of the $\mathrm{Va}$ and VIIIa protolithic coagulation factors. The increase in APC is even bigger due to the protein $\mathrm{S}$ stimulation by HDL, thus exist a synergic anticoagulant effect between $\mathrm{C}$ and $\mathrm{S}$ proteins. That anticoagulant characteristic of HDL is due to the presence of natural anticoagulants, such as cardiolipin and phosphatidyl-ethanolamine. In principle, the HDL also seems to participate of the fibrinolysis process, because although the plasminogen activator inhibitor-1 (PAI-1) secretion is increased (from endothelial cells), even in the hypercholesterolemia and the hypertriglyceridemia, the plasmatic HDL concentration is inversely proportional to the concentrations of PAI- 1 and the tissue plasminogen activator (t-PA). This correlation may reflect the in vitro effect of HDL in PAI-1 and t-PA secretion factors by the endothelium [39]. The modulation of the coagulation process and fibrinolysis by HDL accompanied by the cytokines secretion inhibition, TNF- $\alpha$ and IL-1, which increases the coagulation and the fibrinolysis [38].

It was also found a contrast between the TG-SAH and TG-NSAH levels. According to the literature [40], the raised TG values alter the LDL and HDL metabolism, increasing the atherogenic potential by LDL formation and reducing the cardioprotective action of HDL. The high TG plasmatic levels have been determined and used by clinics as risk elements; it is normally found in patients with premature vascular atherosclerotic disease and it is risk predictive by univariate analysis [41].

The analysis of linear correlation test in this study demonstrates there was a positive correlation between LDL-SAH and TC-SAH. This result already is expected since LDL is a fraction of TC. 
The TC marker presents correlation with TG in the SAH group. This result, according to the literature [42] also is expected because the triglycerides determination is associated with the HDL, it means the ratio between these two biochemical variables is used as a diagnostic parameter to the atherogenicity, because, since the triglycerides are increased, the HDL is reduced, what characterize the inverse proportion between the two fractions, facilitating eve more the laboratorial analysis of cardiovascular diseases.

\section{Conclusions}

Alterations in the endothelial vascular functions, as a response to the mechanical effects (arterial hypertension), immunological and biochemical actions represent the initial physio-pathological step to atherosclerotic disease activation. Once this association is recognized, it is necessary for the maintenance of the arterial pressure control, then reducing the arterial damage risks that can result in severe diseases, including the cardiovascular ones as a cerebral vascular accident (CVA).

Generally, there was higher arterial hypertension prevalence among the masculine gender individuals once compared to the feminine. Therefore, when women achieve the menopause these indexes become the same. Besides, the life habits as smoking, obesity and sedentariness associated with arterial hypertension can raise the chances of cardiologic events.

The obtained results of this study show that the hypertensive patients and the normotensive ones can present or not significant differences among some lipoprotein indexes and other markers; however, the association of life habits as sedentariness, smoking, and obesity alongside the dyslipidaemias, is recognized as risk factors to atherosclerotic disease, indicating that the individual could become a potential atherosclerotic sick patient [sub-clinic atherosclerosis].

Therefore, these factors and markers deserve more attention enforces of health staff of Family Health Strategy, in the course of hypertension and atherosclerosis (sub-clinic) in the studied population, since cardiovascular risks by FRS are bigger ( 2.5 to 2.8 times) than the NSAH ones. The monitoring of medium and high-risk patients should prioritize lifestyle changes, employing preventive measures for hypertension, atherosclerosis and CVD.

\section{Conflicts of Interest}

The authors declare no conflicts of interest regarding the publication of this paper.

\section{References}

[1] Sposito, A.C., Caramelli, B., Fonseca, A.H.F., Bertolami, C.M., et al. (2007) IV Brazilian Guidelines on Dyslipidemias and Prevention of Atherosclerosis. Arquivos Brasileiros de Cardiologia, 88, 1-19.

[2] BAI, Y. and SUN, Q. (2016) Fine Particulate Matter Air Pollution and Atherosclerosis: Mechanistic Insights. Biochimica et Biophysica Acta, 1860, 2863-2868. 
[3] Ribeiro, A.G.R., Cotta, R.M.M. and Ribeiro, M.R. (2012) Health Promotion and Integrated Prevention of Risk Factors for Cardiovascular Diseases. Ciência \& Saúde Coletiva, 17, 7-17.

[4] Santos, M.G., et al. (2008) Risk Factors in the Development of Atherosclerosis in Childhood and Adolescence. Arquivos Brasileiros de Cardiologia, 90, 276-283. https://doi.org/10.1590/S0066-782X2008000400012

[5] Stabelini, N., Bozza, R., Ulbrich, A., et al. (2012) Metabolic Syndrome in Adolescents of Different Nutritional Status. Arquivos Brasileiros de Endocrinologia \& Metabologia, 56, 104-109.

[6] Campelo, R.C.V., et al. (2014) Risk Factors for Atherosclerosis in Brazilian Adolescents. Revista Internacional de Ciências e Saúde, 1, 21-29.

[7] Alencar, Y.M.G., Filho, E.T.C., Paschoal, S.M.P., Curiati, J.A.E., Ping, W.C. and Litvoc, J. (2000) Brazilian Guidelines on Dyslipidemias and Prevention of Atherosclerosis. Arquivos Brasileiros de Cardiologia, 74, 181-188.

[8] Fuchs, F.D. (2004) Sistemic Artery Hypertension. In: Duncan, B.B., et al., Eds., Outpatient Medicine: Primary Care Based on Evidence, Porto Alegre, Artmed, cap, 641-656.

[9] DATASUS (2013) Health Information TABNET. Ministry of Health, Brasília. http://www2.datasus.gov.br/DATASUS/index.php?acao=11\&id=33490

[10] Barreto, M.S., et al. (2018) Non-Use of Routine Consultations in Primary Care by People with Hypertension. Ciência \& Saúde Coletiva, 23, 795-804.

[11] Passos, V.M.A., Assis, T.D. and Barreto, S.M. (2006) Hypertension in Brazil: Prevalence Estimates from Population-Based Studies. Epidemiologia e Serviços de Saúde, 15, 35-45.

[12] Zanesco, A. and Zaros, P.R. (2009) Physical Exercise and Menopause. Revista Brasileira de Ginecologia e Obstetrícia, 31, 254-261.

[13] Pimenta, H.B. and Caldeira, A.P. (2014) Framingham Score Cardiovascular Risk Factors among Hypertensives Attended by Family Health Teams. Ciência \& Saúde Coletiva, 19, 1731-1739.

[14] Dórea, E.L. and Lotufo, P.A. (2004) Epidemiology of Systemic Arterial Hypertension. Revista da Sociedade Brasileira de Hipertensão, 7, 86-89.

[15] Santos, G.E.O. (2016) Sample Calculation: Online Calculator. http://www.publicacoesdeturismo.com.br/calculoamostral/

[16] Malachias, M.V.B., et al. (2016) 7th Brazilian Direction of Hypertension. Arquivos Brasileiros de Cardiologia, 107, 83 p.

[17] Xavier, H.T., Izar, M.C., FariaNeto, J.R., Assad, M.H., Rocha, V.Z., Sposito, A.C. and Brazilian Society of Cardiology V (2013) Brazilian Guideline for Dyslipidemia and Prevention of Atherosclerosis. Arquivos Brasileiros de Cardiologia, 101, 1-22. https://doi.org/10.5935/abc.2013S010

[18] Brazil Ministry of Health (2010) Secretariat of Health Care. Department of Basic Attention. Tracking/Ministry of Health, Department of Health Care, Department of Primary Care, Ministry of Health, Brasília, 95 p.

[19] Camacho, C.R.C., Melicio, L.A.D. and Soares, A.M.V.C. (2007) Atherosclerosis, Aninflammatory Response. Arquivos de Ciências da Saúde, 14, 41-48.

[20] Frohlich, E.D. (1999) Risk Mechanisms in Hypertensive Heart Disease. Hypertension, 34, 782-789. https://doi.org/10.1161/01.HYP.34.4.782

[21] Stamm, A.M.N.F., Meinertz, G., Silva, J.C., Siqueira, M.T.V. and Andrigueti, M. (2008) Systemic Arterial Hypertension, Microalbuminuria and Antihypertensive 
Therapy. Brazilian Journal of Medicine, 65, 139-144.

[22] Coylewright, M., Reckelhoff, J.F. and Ouyang, P. (2008) Menopause and Hypertension: An Age-Old Debate. Hypertension, 51, 952-959. https://doi.org/10.1161/HYPERTENSIONAHA.107.105742

[23] Rocha, M.O.C., Pedroso, E.R.P., Fonseca, J.G. and Silva, O.A. (1998) Clinical Therapy. Guanabara Koogan S.A, Rio de Janeiro.

[24] Contran, S.R., Kumar, V. and Collins, T. (2000) Structural and Functional Pathology. 6 Edition, Guanabara Koogan, Rio de Janeiro.

[25] Marques, A.C.P.R., Campana, A., Gigliotti, A.P., Lourenço, M.T.C., Ferreira, M.P. and Laranjeira, R. (2001) Consensus on the Treatment of Nicotine Addiction. Revista Brasileira de Psiquiatria, 23, 200-214. https://doi.org/10.1590/S1516-44462001000400007

[26] Kannel, W.B. (2000) Risk Stratification in Hypertension: New Insights from the Framingham Study. American Journal of Hypertension, 13, 3-10. https://doi.org/10.1016/S0895-7061(99)00252-6

[27] Neutel, J.M., Smith, D. and Weber, M. (1999) Is High Blood Pressure a Late Manifestation of Hypertension Syndrome? American Journal of Hypertension, 12, 215-223. https://doi.org/10.1016/S0895-7061(99)00107-7

[28] Rueda, F.G., Rodrigues, C.J.A., Lyra, C.H.A., Souza, J.P.J., Gandra, J.M.B. and Vitor, E.G. (2002) Prevalence of Systemic Arterial Hypertension and Dyslipidemia in Employees of the Clinical Hospital of the Federal University of Pernambuco. Anais da Faculdade de Medicina da Universidade Federal de Pernambuco, 47, 46-49.

[29] Nicolau, J.C., Nogueira, C., Maia, L.N. and Ramires, J.A.F. (1998) Evolution of Cholesterol Levels in the Adult Population of São José do Rio Preto (1991-1997). Arquivos Brasileiros de Cardiologia, 71, 699-704. https://doi.org/10.1590/S0066-782X1998001100010

[30] Lessa, I., Conceição, J.L., Souza, M.L., Oliveira, V., Carneiro, J., Melo, J., et al. (1997) Prevalence of Adult Dyslipidemias from Labor Demand in Salvador. Arquivos Brasileiros de Cardiologia, 69, 395-400. https://doi.org/10.1590/S0066-782X1997001200006

[31] Steinberg, D. (1997) Low Density Lipoprotein Oxidation and Its Pathobiological Significance. The Journal of Biological Chemistry, 272, 20963-20966. https://doi.org/10.1074/jbc.272.34.20963

[32] Thompson, G.R., Soutar, A.K., Spengel, F.A., Jadhav, A., Gavigan, S.J.P. and Myant, N.B. (1981) Defects of Receptor-Mediated Low-Density Lipoprotein Catabolism in Homozygous Familial Hypercholesterolemia and Hypothyroidism in Vivo. Proceedings of the National Academy of Sciences of the United States of America, 78, 2591-2595. https://doi.org/10.1073/pnas.78.4.2591

[33] Neaton, J.D. and Wentworth, D. (1992) Serum Cholesterol, Blood Pressure, Cigarette Smoking and Death from Coronary Heart Disease, Overall Findings and Differences by Age for 316099 White Men. Archives of Internal Medicine, 152, 56-64. https://doi.org/10.1001/archinte.1992.00400130082009

[34] Sposito, A.C. (2004) Emerging Insights into Hypertension and Dyslipidaemia Synergies. European Heart Journal Supplements, 6, G8-G12. https://doi.org/10.1016/j.ehjsup.2004.10.003

[35] Korhonen, T., Savolainen, M.J., Koistinen, M.J., Ikaheimo, M., Linnaluoto, M.K., Kervinen, K., et al. (1996) Association of Lipoproteincholesterol and Triglycerides with the Severity of Coronary Arterydisease in Men and Women. Atherosclerosis, 127, 213-220. https://doi.org/10.1016/S0021-9150(96)05958-8 
[36] Fonseca, F.A.H., Kuymijian, W., Izar, M.C.O. and Ihara, S.S.M. (2002) Hypertension and Dyslipidemias. Brazilian Journal of Hypertension, 9, 268-272.

[37] Barter, P.J., Nicholls, S., Rye, K.A., Anantharamaiah, G.M., Navab, M. and Fogelman, A.M. (2004) Antiinflammatory Properties of HDL. Circulation, 95, 764-772. https://doi.org/10.1161/01.RES.0000146094.59640.13

[38] Lima, E.S. and Couto, R.D. (2006) Structure, Metabolism and Physiological Functions of High Density Lipoprotein. Jornal Brasileiro de Patologia e Medicina Laboratorial, 42, 169-178. https://doi.org/10.1590/S1676-24442006000300005

[39] Cuchel, M. and Rader, D.J. (2002) The Role of High Density Lipoproteins in Thrombosis. The Scientific World Journal, 2, 89-95. https://doi.org/10.1100/tsw.2002.85

[40] Packard, C.J. and Saito, Y. (2004) Non-HDL Cholesterol as a Measure of Atherosclerotic Risk. Journal of Atherosclerosis and Thrombosis, 11, 6-14. https://doi.org/10.5551/jat.11.6

[41] Frost, P.H. and Havel, R.J. (1998) Rationale for Use of Non-High-Density Lipoprotein Cholesterol Rather Than Low-Density Lipoprotein Cholesterol as a Tool for Lipoprotein Cholesterol Screening and Assessment of Risk and Therapy. The American Journal of Cardiology, 81, 26B-31B.

https://doi.org/10.1016/S0002-9149(98)00034-4

[42] Vieira, E.A., Carvalho, W.A., Aras-Júnior, R., Couto, F.D. and Couto, R.D. (2011) Triglyceride/HDL-C Ratio and High Sensitivity C-Reactive Protein in Cardiovascular Risk Assessment. Jornal Brasileiro de Patologia e Medicina Laboratorial, 47, 113-118. https://doi.org/10.1590/S1676-24442011000200004 